\title{
A pesquisa científica paulista em biociências: à margem das instituições
}

\section{Scientific research in the biosciences in São Paulo: beyond institutions}

Gildo Magalhães dos Santos

Professor de história da ciência, Universidade de São Paulo (USP)

Rua Luísa Cecco Leonardi, 111 04789-120 São Paulo - SP Brasil

gildomsantos@hotmail.com
SANTOS, G. M. dos: A pesquisa científica paulista em biociências: à margem das instituições.

História, Ciências, Saúde - Manguinhos, v. 12, n. 1, p. 51-67, jan.-abr. 2005.

A criação dos institutos científicos foi um marco na história do estado de São Paulo durante a primeira metade do século XX, devido ao seu papel inovador e às suas ligações com o desenvolvimento industrial e econômico dessa região. Essas instituições abrangeram várias áreas básicas e aplicadas, fomentando linhas de pesquisa pioneiras. As transformações no cenário político da segunda metade do século, exacerbadas pela falta de continuidade da política de administração científica e tecnológica, levaram à progressiva deterioração e à virtual estagnação da pesquisa na maioria dos institutos paulistas. A partir de um curso em história das ciências para graduação em biologia, foram realizadas entrevistas com pesquisadores que vivenciaram as mudanças ocorridas. O resultado compõe uma abordagem de história oral que documenta as percepções da comunidade de pesquisadores científicos em torno de suas próprias realizações e dos caminhos das respectivas instituições ao longo dos últimos decênios.

PALAVRAS-CHAVE: estado de São Paulo, institutos de pesquisa, política científica.

SANTOS, G. M. dos: Scientific research in the biosciences in São Paulo: beyond institutions.

História, Ciências, Saúde - Manguinhos, v. 12, n. 1, p. 51-67, Jan.-Apr. 2005.

During the first half of the twentieth century, the creation of scientific institutes was a landmark in the history of the State of São Paulo, given their innovative role and their relation to the region's industrial and economic development. These institutions encompassed a number of basic and applied areas and fostered pioneering lines of research. The transformations that occurred in the political arena during the latter half of the century, exacerbated by the lack of continuity in policies regarding scientific and technological management, brought the progressive deterioration and virtual stagnation of research in most São Paulo institutes. Under my guidance, undergraduate students of biology who were enrolled in a course in the history of science conducted interviews with researchers who had lived through these changes. This oral history approach documents the perceptions of this community of scientific researchers regarding their own achievements and the paths their institutes have followed in the last decades.

KEYWORDS: São Paulo state, research institutions, scientific policy. 


\section{Introdução e breve histórico da pesquisa nos institutos paulistas}

$\mathrm{O}$ presente trabalho resultou da disciplina de história da ciência, ministrada durante 2002 para alunos dos últimos anos dos cursos diurno e noturno de biologia da Universidade de São Paulo. Sua proposta consistiu em realizar entrevistas, sob orientação do autor, de profissionais trabalhando na área de biociências em institutos de pesquisa do governo paulista. $\mathrm{O}$ objetivo era traçar um perfil da auto-imagem construída pelo pesquisador científico de instituto estatal, que é um profissional empregado fora da chamada vida acadêmica ou universitária, para identificar a situação em que este se vê, e como ele a relaciona com seu contexto institucional e social contemporâneo. Essa categoria profissional está ligada a instituições outrora já reconhecidas como centros pujantes da pesquisa científica-tecnológica do estado e que atualmente passam por grave crise de vocação e de valorização. Como subproduto desejava-se que os alunos pudessem ter contato com uma realidade mal conhecida por eles e, de resto, pela sociedade em geral.

Para se ter uma perspectiva mais ampla do objeto das entrevistas é conveniente regredir aos primórdios da institucionalização da pesquisa científica em terras paulistas. Já havia uma atividade de pesquisa desenvolvida ao abrigo dos museus desde o século XIX, mas a criação de institutos específicos vai ocorrer grosso modo por volta da virada para o século XX. Um debate intenso que ocorreu durante todo o Império e que continuaria pelo período republicano envolvia a questão de o Brasil ser uma nação predominantemente agrária, em detrimento da indústria manufatureira. A expansão da lavoura cafeeira no centro-oeste do estado de São Paulo, a partir da primeira metade do século XIX, resultou na formação de capitais que possibilitaram à economia local tomar a

${ }^{1}$ Este é um assunto que já foi intensamente pesquisado, e do qual há interpretações diversas, por vezes opostas, sendo porém inegável a influência recíproca entre a atividade agrícola do café e o processo de industrialização brasileira, especialmente em São Paulo. Ver, por exemplo, Pereira (1984) e Silva (1976). dianteira no país em termos de investimentos para modernização e industrialização. ${ }^{1}$

A chegada da mão-de-obra imigrante para trabalhar no campo e nas fábricas, bem como o intenso intercâmbio comercial e a maior atividade portuária, fizeram com que o governo estadual desse maior atenção à saúde e à luta contra moléstias epidêmicas, ao saneamento urbano e à melhoria da produção agrícola, tanto na cidade portuária de Santos quanto na capital do estado, bem como em seu interior, preocupações de resto também incidentes na capital brasileira, com a conhecida atuação de Oswaldo Cruz em Manguinhos, bem como de outras personalidades da saúde pública.

Para essas finalidades, foi necessário que o Estado paulista fundasse uma série de institutos de pesquisa, o que se consolidou basicamente no período da República Velha (1889-1930), conquanto 
2 A pesquisa de ciências naturais levada a cabo nos museus brasileiros no século XIX se encontra descrita em Lopes (1997). Para algumas análises pertinentes da institucionalização da ciência no período republicano, em especial na área da saúde, ver Ribeiro (1993), Almeida e Dantes (2001), Teixeira e Almeida (2003).

${ }^{3}$ Ver Vargas (1994). As datas citadas de criação dos institutos nem sempre coincidem com aquelas divulgadas nas publicações ou páginas da Internet, porque às vezes é considerado o início efetivo das atividades antes dos respectivos decretos

governamentais, ou inversamente houve institutos que começaram só no papel, mas na prática entraram em funcionamento depois. algumas instituições só fossem efetivamente inauguradas mais tarde. ${ }^{2} \mathrm{Na}$ área da saúde, foi fundado o Instituto Vacinogênico em 1892, que fabricou vacina contra a varíola e trabalhou em estreita colaboração com o Instituto Bacteriológico de São Paulo, criado em 1893, que atuou com sucesso no diagnóstico laboratorial de várias doenças já nos seus primeiros anos de funcionamento, como por ocasião dos surtos de peste bubônica na capital e de febre amarela em Santos. O Instituto Butantã, criado em 1899-1900 e inicialmente anexo ao Bacteriológico, destinou-se no começo à produção de soros antiofídicos, mas depois estendeu sua atuação para outras áreas da saúde. Entre 1924 e 1927 se estruturou o Instituto Biológi$\mathrm{co}$, com a finalidade inicial de combater a broca-do-café, acabando também por diversificar suas atividades de pesquisa pela microbiologia e outros campos. ${ }^{3}$

Em 1896 surgiu o Instituto Florestal de São Paulo, ao passo que a Imperial Estação Agronômica de Campinas, organizada em 1887, adquiriu maior relevância a partir da década de 1920, já com o nome de Instituto Agronômico de Campinas. Como resultado desse esforço científico e tecnológico, a agronomia do estado foi bem-sucedida, com vitórias históricas contra pragas tais como a já citada broca-do-café, o que acabou beneficiando o resto do país nesse campo. Ao mesmo tempo, a força de trabalho no campo e na cidade teve sua saúde mais bem cuidada. A valorização pelo Estado dessas facetas mais utilitárias da pesquisa esteve assim inequivocamente associada à expansão da fronteira agrícola e urbana para o oeste de São Paulo.

Não significou esse esforço institucional a existência de uma política pública consciente e consistente voltada para a ciência como um todo, mas a percepção por parte de parcela da elite paulista de que o fortalecimento dos institutos de pesquisa estava de certa forma ligado ao crescimento econômico; um fator determinante para que São Paulo viesse a se destacar entre os demais componentes da federação brasileira. Pode-se dizer que esse modelo adotado com razoável sucesso pelo governo paulista acabou criando raízes que permaneceram e mesmo chegaram a servir de inspiração para alguns outros estados.

Atualmente, há uma carreira de pesquisador científico em São Paulo, que congrega todos os profissionais dos 16 institutos sob administração direta do governo, distribuídos por quatro secretarias de Estado, as da Agricultura e Abastecimento (Instituto Agronômico, Instituto Biológico, Instituto de Economia Agrícola, Instituto de Pesca, Instituto de Tecnologia de Alimentos, Instituto de Zootecnia), do Meio Ambiente (Instituto de Botânica, Instituto Florestal, Instituto Geológico), do Planejamento (Instituto Geográfico e Cartográfico) e da Saúde (Instituto Adolfo Lutz, Instituto Butantã, Instituto de Infectologia Emílio Ribas, Instituto Lauro de 
${ }^{4}$ Foram incluídas neste número também as entrevistas com dois pesquisadores estatais, embora fora dos institutos, trabalhando respectivamente em uma fundação (Oncocentro, estabelecida em 1974) ligada à Secretaria da Saúde, e na Secretaria do Meio Ambiente (de existência mais recente, instituída em 1986), porque suas atividades tinham características semelhantes às dos demais entrevistados.
Souza Lima, Instituto Pasteur, Instituto de Saúde). Além desses institutos, há outros órgãos ligados às secretarias, que deixamos de mencionar porque estão em geral mais relacionados com aspectos de produção ou administração e não diretamente com a pesquisa científica em biociências.

\section{Metodologia adotada}

Inicialmente montou-se uma espinha dorsal do que seria a entrevista e foram repassadas com os alunos algumas instruções básicas para trabalhos de história oral. Estabeleceram-se então contatos com pesquisadores de diversos institutos paulistas que possuíssem experiência e tivessem vivido pelo menos parte das transformações cuja essência se pretendia captar. O roteiro da entrevista começava pelo levantamento de dados pessoais e profissionais do entrevistado, sua vida acadêmica, inclusive como havia sido definida sua vocação e como havia transcorrido a sua trajetória profissional. A seguir, solicitava-se que o pesquisador fizesse um apanhado histórico de sua instituição, para então avaliar suas atuais dificuldades e facilidades, suas relações com empresas privadas e órgãos fomentadores de pesquisa. Finalmente, pedia-se uma avaliação da carreira de pesquisador científico, tanto interna quanto externamente à instituição.

Dentre as entrevistas realizadas foram selecionadas as de 32 pesquisadores ${ }^{4}$ que atuam em cinco institutos estatais: os já mencionados Institutos Butantã e Biológico, além do Botânico (datado oficialmente de 1938), da Pesca (criado em 1969) e o de Economia Agrícola (de 1943). Embora haja no estado quase duas dezenas de institutos, pode-se considerar que a amostra tem uma certa representatividade do conjunto, devido ao renome internacional de algumas das instituições mencionadas e porque os institutos escolhidos empregam parte considerável do total de pesquisadores da categoria no estado de São Paulo. Destaque-se ainda que foram entrevistados pesquisadores que, embora trabalhando com pesquisas em biociências, tinham outras formações básicas que não a de biólogo.

\section{As entrevistas}

As tabelas 1 e 2, a seguir, apresentam as quantidades de pessoas entrevistadas, suas instituições e alguns dados gerais da amostragem feita. $\mathrm{O}$ material recolhido revelou-se bastante rico e se presta a uma série de análises; no presente trabalho são apresentadas algumas das primeiras possibilidades. 
Tabela I - Experiência e Qualificação

\begin{tabular}{lr}
\hline Homens & 14 \\
Mulheres & 18 \\
Graduados & 4 \\
Mestres & 5 \\
Doutores & 18 \\
Pós-doutorados & 5 \\
Idade média & 50 anos \\
Experiência média & 22 anos \\
\hline Total & $\mathbf{3 2}$
\end{tabular}

Tabela 2 - Formação Básica dos Entrevistados

\begin{tabular}{lcccccc}
\hline Instituição & Biologia & Agronomia & Farmácia & Biomédicas & Medicina & Total \\
\hline Instituto Butantã & 7 & - & 6 & 1 & 2 & 16 \\
Instituto Biológico & 4 & 1 & - & - & - & 5 \\
Instituto Botânico & 6 & 1 & - & - & - & 7 \\
Economia Agrícola & - & 1 & - & - & - & 1 \\
Instituto da Pesca & 1 & - & - & - & - & 1 \\
Secretaria do Meio Ambiente & 1 & - & - & - & - & 1 \\
Fundação Oncocentro & 1 & - & - & - & - & 1 \\
\hline Total & $\mathbf{2 0}$ & $\mathbf{3}$ & $\mathbf{6}$ & $\mathbf{I}$ & $\mathbf{2}$ & $\mathbf{3 2}$ \\
\hline
\end{tabular}

Verifica-se de imediato a alta qualificação dos profissionais entrevistados em termos de titulação e experiência com pesquisa. Indagados com relação a uma auto-análise da vocação para a área de biologia, muitos pesquisadores declararam que foram influenciados por bons professores do colegial, ou que sempre tiveram uma curiosidade natural com relação ao estudo da vida, citando alguns que faziam 'pesquisas' ainda quando crianças ('com pequenos animais').

Quanto à decisão de seguir uma carreira de pesquisador científico em órgão estatal, uma parte significativa afirmou que durante a formação universitária já se inclinava para a atividade de pesquisa, ou nela tinha feito bons estágios de iniciação científica, com orientadores eficientes, o que lhes possibilitou uma oportunidade de emprego antes de se formar; ou ainda, que sempre consideraram importante a atividade da descoberta. Chama a atenção também a resposta de alguns entrevistados de que foram fazer pesquisa por não gostarem de dar aula.

As maiores dificuldades consideradas para o desempenho da função de pesquisador foram os baixos salários, cuja degradação acentuada foi relacionada por diversos entrevistados diretamente 
com a política neoliberal inaugurada no governo Collor e continuada no período presidencial de Fernando Henrique Cardoso e, em São Paulo mais especificamente, a partir da década de 1990 com os governos estaduais do PSDB, como se depreende dos seguintes trechos de algumas entrevistas: "A carreira é muito bem estruturada, o Governo atual (PSDB) é que quer acabar com ela"; "O Governo (...) está saindo da pesquisa"; "é uma atitude deliberada do Governo atual no estado de sucatear os institutos, levando-os à extinção".

Há uma enorme defasagem de salários do pesquisador estadual em comparação com a universidade estadual, para pessoas com a mesma formação. Isto não é uma simples imagem de 'primo pobre', pois a comparação das respectivas tabelas de vencimentos mostra que a diferença chega a ser em média 50\% a menos nos institutos.

Entre outras conseqüências dessa diferenciação, foi mencionado, nas entrevistas, que esse descompasso foi o motivo para a perda de pós-graduandos que passaram pelos institutos de pesquisa paulistas e se sentiam vocacionados para a pesquisa (e não para a vida universitária), mas que acabaram indo trabalhar em centros de pesquisa no exterior. Neste sentido, mesmo reconhecendo que os salários nas universidades públicas paulistas também são baixos em face do preparo profissional exigido, a categoria de professor universitário é considerada relativamente 'privilegiada' pelos pesquisadores dos institutos.

Igualmente deletéria para a atividade do pesquisador científico foi considerada a falta de verbas diretamente alocadas pelo governo estadual para a pesquisa. Em uma das instituições mais tradicionais (Instituto Biológico), o número de pesquisadores reduziu-se de dois mil para setecentos num período de poucos anos em conseqüência da política neoliberal no estado, como foi afirmado por entrevistados.

Foi ainda citado o excesso de burocracia como entrave à pesquisa. Mais grave é que o desvio dos institutos para atividades de 'serviços', diferentes daquelas de pesquisa, foi denunciado por quase todos os pesquisadores, o que se evidencia em diversas mazelas, como:

- falta de concursos públicos para ingresso na carreira de pesquisador científico, sem reposição dos quadros aposentados ou falecidos;

- perda da qualificação profissional, considerada antes mais completa;

- desaparecimento dos técnicos de nível médio, ocasionado tanto por problemas de salários ínfimos - pesquisadores com nível universitário - quanto pela falta de concursos nesse nível (às vezes há vinte anos), acarretando sobrecarga para o pessoal de nível superior e dificuldades para as pesquisas, além da pura 
5 As pesquisas brasileiras para identificar as seqüências de nucleotídeos em material genético começaram com a Fapesp coordenando uma rede de instituições nacionais de pesquisa em 1997, dando origem ao seu Projeto Genoma. O primeiro objeto do projeto foi a bactéria Xylella fastidiosa, causadora da praga do 'amarelinho' na laranja, uma doença que causa perdas na produção de um produto de grande importância

econômica na pauta de exportações do país e cujo código foi determinado em 1999, com repercussão internacional. $\mathrm{O}$ segundo projeto foi do genoma da canade-açúcar, iniciado a seguir e com resultados já em 2000 . O genoma humano do câncer, estudando os tumores mais

freqüentes no Brasil, começou em 1999 e vem continuando desde então. Em 2001, a Fapesp começou a financiar $o$ seqüenciamento do genoma do eucalipto e em 2002 foi terminado o estudo genômico das variedades de bactérias que causam o cancro cítrico e outras doenças em vegetais. Nesse mesmo ano de 2002 foram também iniciados sob patrocínio da Fapesp estudos genômicos do Schistossoma mansoni - parasita causador da esquistossomose -, além de outros fitopatóge-nos da cana-de-açúcar, videiras e plantas ornamentais. falta de técnicos que saibam operar corretamente certos equipamentos.

Igualmente faltam verbas para atividades de rotina, envolvendo equipamentos, material de pesquisa, serviços de manutenção, material de consumo e pagamento de serviços prestados por terceiros (tais como fotografias, análises químicas etc.). Algumas citações pessoais sobre estes fatos são indicações pungentes do que vem ocorrendo: "não há funcionários para fazer limpeza da instituição"; “o microscópio eletrônico de varredura (...) não está sendo utilizado por falta de técnico para manuseá-lo"; "toda a minha vida profissional foi aqui e é uma pena presenciar a deterioração material e humana que vem ocorrendo".

Significativamente, uma parte relevante da comunidade entrevistada considerou que o excessivo empenho da Fundação de Amparo à Pesquisa do Estado de São Paulo (Fapesp) em financiar o Projeto Genoma ${ }^{5}$ prejudicou a maioria das demais pesquisas, que, ao contrário daquele projeto, não despertam nem de longe a atenção da mídia. Esta queixa de retração das agências fomentadoras de pesquisa se estende às verbas federais, como as do Conselho Nacional de Desenvolvomento Científico e Tecnológico (CNPq) e da Coordenação de Aperfeiçoamento de Pessoal de Nível Superior (Capes). Nas palavras dos entrevistados: "o que na verdade deveria ser feito era desenvolver um trabalho nosso, brasileiro (...) deveríamos ter mais ciência pura e não um pragmatismo com apenas procedimentos técnicos, como no Projeto Genoma"; "Fapesp ou $\mathrm{CNPq}($...) acham que a biologia molecular resolve tudo"; "a Fapesp mudou após apoiar projetos de genoma, está mais difícil de obter financiamento".

Esta situação de penúria veio se somar a uma já histórica falta de atenção do governo para com os institutos, no dizer de vários entrevistados: "as pesquisas diminuíram drasticamente pela falta de interesse de parte dos dirigentes e do governo".

Também foi significativo o número de entrevistados que se queixaram de que houve preterição da pesquisa nos institutos depois que se consolidou no país a pós-graduação universitária, para onde foram concentrados os recursos financeiros e as atenções do estado em termos de pesquisa. Este é um fenômeno muito comentado nos institutos, mas pouco investigado ou mesmo sem ressonância quando são levadas em conta as avaliações sobre a política científica publicadas pela comunidade científica mais ampla, isto é, fora dos institutos.

Quanto aos resultados da carreira profissional, as respostas foram bastante divididas, embora predominasse o sentimento de decepção. Cerca de um terço dos entrevistados afirmam que as pesquisas são bem avaliadas por pessoas de fora das instituições às quais pertencem, enquanto que um terço declara que elas não são entendidas e os demais ainda afirmaram que as pesquisas são bem 
recebidas apenas quando "resolvem diretamente problemas de saúde pública", talvez um reflexo de longo prazo da percepção pública das motivações históricas ligadas à criação dos institutos.

Há um consenso de que falta no país a divulgação à população como um todo dos resultados da pesquisa científica nos institutos, tanto a básica quanto aplicada, e de que as revistas científicas nacionais deveriam ser fortalecidas. As respostas mais freqüentes apontam para a necessidade de melhor divulgação pública e maior atenção da mídia para o que se faz nos institutos de pesquisa. Algumas citações interessantes a esse respeito foram: "Eu acho que o principal seria divulgar melhor o que a gente faz"; "os moradores, apesar de estarem ao lado do instituto, não sabem o que é feito ali"; "A população em geral desconhece a produção científica e suas repercussões, exceto em casos diretamente ligados à saúde, ou quando resolvem uma questão como a do amarelinho da laranja".

Um terço dos entrevistados declarou que suas pesquisas chegaram a despertar interesse na iniciativa privada, mas a totalidade acha que suas pesquisas devem continuar nas mãos do Estado já que, nas suas palavras, "a pesquisa que eu faço tem de ser financiada pelo Estado porque é de longo prazo"; "as instituições públicas favorecem o acesso às descobertas pelos excluídos".

Nestas respostas fica patente a percepção pela comunidade de pesquisadores dos institutos de que a estimulação de parcerias com o setor privado tem como contrapartida o fato de que os resultados das pesquisas não são tornados públicos, apesar de terem sido utilizados recursos públicos. A respeito da prática recente de substituição de pesquisadores científicos oficiais por pesquisadores terceirizados, na forma de 'agências', há uma grave acusação: "essas agências que montaram agora (...) são todas pessoas contratadas com altos salários, e o pesquisador está aqui embaixo, que é concursado e não tem valor algum".

Os pesquisadores afirmaram que muitas vezes não têm contado nem com o apoio dos dirigentes dos seus próprios institutos, uma vez que eles costumam ser designados como ocupantes de cargos políticos, e não motivados pela competência científica ou administrativa, sendo que às vezes nem conhecem a 'cultura da casa' que dirigem. Alguns exemplos dessas opiniões: “O secretário (que responde pelos institutos) vai à televisão e fala da pesquisa na universidade e não da pesquisa dos institutos, que é a casa dele!"; “o gerenciamento está na mão do governo estadual e não na de um administrador da instituição (...) isto dificulta as negociações, contratações (...) a mentalidade dos gerenciadores não acompanha as necessidades do instituto".

A maioria dos entrevistados se ressente da falta de atenção não só do governo ou de seus diretores, mas também das agências financiadoras de projetos, notadamente da Fapesp; além disso, os 
${ }^{6}$ Para três tentativas diferentes de conceituação de ciência, técnica, tecnologia, pesquisa básica e aplicada, conquanto reflitam diversos problemas não resolvidos, ver Vargas (1985), Bunge (1980) e Gama (1987) entrevistados se ressentem da falta de atenção dos órgãos do governo federal, como citado anteriormente em conexão com o Projeto Genoma. Além disso, há uma percepção de que tais instituições de fomento não reconhecem devidamente as pesquisas e os pesquisadores nacionais, pois se houver pesquisadores estrangeiros associados há mais chances de se contar com financiamentos brasileiros.

Com tantos aspectos negativos, chega a ser surpreendente que dois terços dos entrevistados tenham se declarado ao final bastante otimistas e nem um pouco pessimistas com relação ao futuro da carreira de pesquisador no Brasil. Quase todos afirmaram explicitamente que recomendariam seguir seu exemplo vocacional para um jovem em busca de uma carreira significativa e importante para o país porque, como disse um deles, "eu acho que o importante é ser idealista".

\section{Pesquisa básica e aplicada}

Uma queixa bastante comum ao longo das entrevistas foi a do abandono e do desaparecimento da pesquisa básica nas instituições governamentais, correlacionados à exigência de resultados práticos e à visão das autoridades de que os institutos deveriam se dedicar unicamente à pesquisa aplicada. Observe-se a esse respeito que as relações entre ciência, técnica e tecnologia têm sido objeto de muitas tentativas de esclarecimento e delimitação, ${ }^{6}$ na verdade sem muito sucesso e freqüentemente eivadas de contradições.

Dessa discussão intrincada, cabe apenas ressaltar que por vezes ocorre que uma técnica preceda sua respectiva ciência, ou que algumas técnicas se desenvolvam em íntima conexão com as ciências puras que lhes são paralelas, sendo que a ciência 'pura', ou 'básica', embora muito raramente constitua um fator imediato, não obstante é essencial à inovação (Ziman, 1981). Em conseqüência, a fronteira entre o que é básico e o que é puro torna-se bastante tênue, sendo comum que a linha divisória seja adotada em função de conveniências externas à pesquisa, de forma que se torna difícil uma distinção de caráter bem unívoco entre elas.

Como exemplo histórico dessa zona cinzenta, lembramos que a modernização do Japão na Era Meiji, a partir de 1868, acarretou o rápido desenvolvimento científico do país, e parte da explicação do sucesso dessa empreitada está no fato de que, ao contrário da Europa, não houve entre os japoneses uma preocupação com a diferenciação rígida entre ciência básica e prática (Pyenson e SheetsPyenson, 1999).

Em algumas das instituições dos entrevistados há uma opinião mais ou menos generalizada de que, apesar de coexistirem as áreas de pesquisa básica e pesquisa aplicada, há desequilíbrio na distribuição de verbas entre elas. Usando o conhecido exemplo da des- 
7 Em 1948, Maurício Rocha e Silva e sua equipe descobriram no veneno da jararaca a bradicinina, substância poderosa para abaixar a pressão arterial. Pesquisadores brasileiros posteriormente isolaram as toxinas que poten-cializam a bradicinina, mas o mérito ficou com o inglês John Vane, que ganhou o prêmio Nobel com um anti-hipertensivo que foi patenteado pela Squibb, com grande sucesso econômico em um mercado bilionário. Há novas pesquisas com venenos ofídicos atualmente em curso no Instituto Butantã que têm potencial para ampliar a atuação de anti-hiper-tensivos (Izique, 2001). coberta no Instituto Biológico de São Paulo de drogas poderosas no controle da pressão arterial, ${ }^{7}$ vários pesquisadores dessa área disseram que "um anti-hipertensivo veio do isolamento de uma toxina do veneno da (...) jararaca, e tudo começou com uma pesquisa básica"; "o medicamento que é obtido a partir do veneno de serpentes (...) foi descoberto a partir da pesquisa básica (...) [e ele] é difundido no mundo inteiro, gerando bilhões de dólares para os laboratórios que desenvolveram este produto, e os brasileiros que deram o passo inicial estão chupando o dedo"; "a gente descobre, quem tem recursos faz o desenvolvimento, e nós ainda somos obrigados a importar e trazer para cá".

Nos institutos, as pesquisas talvez difiram daquelas empreendidas nas universidades devido a serem mais incentivadas para partir da área básica até se transformarem em um produto, através da pesquisa aplicada, embora nem sempre surja uma aplicação direta. Uma hipótese refletida nas entrevistas que poderia explicar a situação de descaso dos institutos é que este poderia estar diretamente ligado à falta de conhecimento por parte dos administradores institucionais e dos governos desse inter-relacionamento entre pesquisa básica e aplicada, como se depreende de alguns dos depoimentos: "a carreira tende a se extinguir por não atender diretamente aos interesses do Estado, que não tem a pesquisa básica como prioridade (...) se distanciando do atendimento às políticas públicas"; " A maioria dos pesquisadores tem-se dedicado à pesquisa aplicada, sendo que a básica está sendo marginalizada. Isto acarretará sérios problemas por falta de conhecimentos que embasem os estudos mais aplicados".

Aparentemente houve uma tentativa de sobrevivência dos institutos pelo seu afastamento da pesquisa considerada básica em direção a pesquisas que pudessem ter aplicação comercial, mas os entrevistados disseram que mesmo essa motivação mais comercial não os salvou da decadência, com o agravante de que "as bolsas não estão mais sendo dadas, existe uma colaboração muito mais com a indústria do que com a formação estudantil"; "aqui é instituição de pesquisa e produção, mas a prioridade é muito mais produção do que pesquisa (...), [só que] (...) a pesquisa básica é a que mais produz (...)"; "não tem muito interesse das empresas privadas em fazer pesquisa";"nós poderíamos estar produzindo trigo no Brasil se houvesse mais investimento na pesquisa [básica]".

A difícil inserção do país no cenário internacional como produtor de conhecimento seria então mais árdua porque não se investe na pesquisa básica: "as empresas nacionais (...) importam tudo que vem de fora"; "o Brasil é um país produtor, aqui não se formam pensadores".

Pensando na relação entre sociedade, pesquisa e desenvolvimento, poder-se-ia retomar uma idéia simples proposta por Milton Vargas 
8 Esses dados foram extraídos de Vogt e Stal (1994), e não consta que tenha havido melhora significativa desde esta publicação, apesar de muitos discursos oficiais otimistas em contrário.
(1994), segundo a qual na sociedade há um sistema tecnológico composto de vários subsistemas que interagem entre si:

- a ciência, através das universidades e centros de pesquisa a ela associados;

- a tecnologia, propriamente dita, desenvolvida em laboratórios privados ou institutos de pesquisa estatais, sendo que estes e aqueles deveriam por sua vez estar ligados a programas de pósgraduação;

- o sistema produtivo, representado por empresas de engenharia, pela indústria, agricultura e serviços;

- uma série de 'filtros sociais', cuja função é intermediar o público consumidor e os subsistemas, e de que são exemplo agências governamentais, associações de classe, a opinião pública etc.

No Brasil, cremos que tal sistema tecnológico até já existe, e em alguns setores chega mesmo a ser importante, mas no geral o país ainda não tem grande destaque dentro da comunidade científica e tecnológica internacional, o que constitui uma prova cabal de seu atraso, e não do eufemismo freqüentemente repetido de que é um país "em desenvolvimento". Alguns dados ilustram o problema:

- os recursos para pesquisa básica do governo federal vêm caindo - a queda de 1980 para 1992 foi de sete vezes;

- nos países desenvolvidos, a indústria financia em média cerca de $50 \%$ dos gastos em pesquisa - na Alemanha esse valor chega a $60 \%$ e no Japão a $70 \%$, enquanto que no Brasil esses gastos estão na faixa de $20 \%$;

- os EUA gastam em pesquisa científica um valor absoluto de 750 vezes mais do que o Brasil, para uma relação de produto bruto vinte vezes maior;

- os gastos públicos com educação por habitante eram dez vezes superiores nos EUA com relação ao Brasil, investimento que lá se concentra maciçamente no ensino de $1^{\underline{o}}$ e $2^{\circ}$ graus (Ensino Funamental e Ensino Médio), enquanto que aqui se concentra no ensino superior.

\section{Considerações finais}

Os resultados das entrevistas atenderam os objetivos pretendidos, principalmente no que concerne à exposição de uma realidade surpreendentemente desconhecida no curso de graduação em biociências, qual seja a carreira de pesquisador científico no estado, pois diversos alunos concluíram que iriam se formar sem jamais ter ouvido falar desse assunto e sem ter tido nenhum contato durante sua vida acadêmica com esta profissão, que representa parte do seu mercado de trabalho. 
${ }^{9}$ Este problema é antigo, já ocorrendo desde o século XIX, conforme conclui Maria Amélia Dantes (1980) sobre a disparidade de salários entre professores universitários e profissionais dos institutos de pesquisa, resultante da inexistência de um reconhecimento social da função desempenhada pelo pesquisador.

10 Parece-nos que esta situação de crise de identidade entre institutos e universidade se passa também em Portugal e outros países, como pudemos observar recentemente, mas sem o caráter perverso da discriminação salarial que há no Brasil contra os pesquisadores dos institutos.

11 Este foi um problema amplamente denunciado pelo menos na Faculdade de Filosofia, Letras e Ciências Humanas da USP, por ocasião da greve geral $\mathrm{e}$ histórica de 2002, motivada pela necessidade de contratação de professores, mas cremos que a situação se repete em outras universidades.
Com base em alguns depoimentos mais extensos e contundentes, de que aqui reproduzimos apenas partes, as conclusões parecem sombrias e não resultam de um simples rosário de lamentações genéricas. As mudanças constatadas confirmam que a carreira do pesquisador nos institutos se degradou com relação aos relatos do início da institucionalização, e a pesquisa nos institutos passou a ser considerada pelas autoridades de importância secundária em face da pesquisa universitária, mesmo quando alguns institutos se credenciaram para a pós-graduação. ${ }^{9}$

Outras fontes de informação, como as publicações oficiais dos institutos e as estatísticas estaduais, compreensivelmente não refletem as preocupações externadas através dos depoimentos colhidos com os entrevistados que, como ressaltamos atrás, são pesquisadores de comprovada senioridade. Embora as entrevistas não tenham contemplado a opinião dos pesquisadores universitários estaduais, que poderiam fazer um contraponto aos pesquisadores dos institutos também estaduais, é fato inegável que estes têm um salário bem menor do que aqueles, teoricamente para a mesma função final de prestação de um serviço público, o que já indica que se trata de um problema real. ${ }^{10}$

Lembre-se ainda de que há um reverso da medalha também problemático na relação entre ensino e pesquisa, pois uma queixa comum ouvida nas universidades é de que uma parcela não desprezível dos professores mais titulados desdenha sua atividade docente, preferindo se dedicar justamente às pesquisas. Apesar da falta de dados para estimar melhor esse fenômeno, cremos que ele é real e até se escuda em uma aceitação tácita de que este comportamento acaba sendo justificável, porque através do conhecido sistema de avaliação em uso a pesquisa e não o ensino é que rende mais prestígio, mais verbas e mesmo, em alguns casos, maior remuneração final do que dar aulas. É conhecida a urgência no meio universitário de 'publicar ou morrer', mas essa prática ignora a advertência séria que fez um dos entrevistados, sintomaticamente um renomado decano da pesquisa científica no Brasil: "se você não publica, não tem apoio da Fapesp, (...) [porém] mais importante do que a quantidade de pesquisas publicadas é a qualidade destas".

Como resultado da situação de desprezo de muitos professores pela atividade didática, não é difícil encontrar nas universidades turmas que são instruídas por profissionais que sequer se dão ao trabalho de preparar suas aulas ou que as delegam para seus alunos de pós-graduação, decaindo então a qualidade geral do ensino. ${ }^{11}$

As pesquisas nas universidades estaduais paulistas e financiadas pela Fapesp têm como fonte orçamentária uma porcentagem do imposto (ICMS) arrecadado constitucionalmente (assim como a própria dotação orçamentária das universidades públicas do estado), enquanto que os institutos estatais dependem dos sabores da 
política, pois suas verbas vêm dos orçamentos governamentais periodicamente destinados às secretarias, sujeitos a cortes, contingenciamentos e transferências.

Criou-se assim uma situação de fato, em que a Fapesp não apenas precisa 'complementar' pesquisas dos institutos - ela acaba em parte suprindo as várias deficiências institucionais e de investimento por parte do próprio governo estadual que abriga aquela financiadora de projetos de pesquisa, conforme registrado nos depoimentos dados pelos entrevistados.

Em contrapartida, historicamente a pesquisa e o desenvolvimento científico e tecnológico no Brasil sempre estiveram mais a cargo do governo do que da iniciativa privada, e com grande descontinuidade na sua intensidade. Afora surtos do tipo verificado em certos períodos dos governos, que ocorrem praticamente desde a época de Dom João VI e que são intermitentes e de duração relativamente curta, foram sempre circunstanciais os demais esforços de pesquisa científica com resultados amplamente reconhecidos pela sociedade. São exemplos dessas exceções, não resta dúvida, o sucesso dos sanitaristas dedicados no começo do século $X X$ à erradicação de epidemias, ou as pesquisas voltadas para a agricultura - como a do Instituto Agronômico de Campinas para salvar a cafeicultura - e que estão na gênese dos institutos paulistas de pesquisa.

Certamente é justo reconhecer que houve também um legado positivo de continuidade a partir desses trabalhos, mas não seria errar muito, à luz da história da ciência em nosso país, dizer que a escala das pesquisas voltadas para o homem brasileiro, em qualquer de suas esferas de necessidade, é bastante reduzida, e que o esforço das pesquisas muitas vezes foi abortado após um início promissor. No caso dos depoimentos colhidos no presente trabalho, observou-se que sobrevivem os pesquisadores e suas pesquisas, sobretudo aqueles dos institutos governamentais, mais à custa de esforços individuais, por sua carga de idealismo profissional ou em última instância por falta de alternativas, em meio à grande penúria de recursos e salários aviltados.

De fato não têm havido diretrizes efetivas e duradouras na condução de uma política nacional de ciência e tecnologia, apenas um discurso de pouco resultado, com honrosas exceções - daí a ciência brasileira ser em resultados ainda muito inferior à de países muito menores, como Israel (Vogt e Stal, 1994). Mesmo considerando programas de excelência sustentados no estado de São Paulo pela Fapesp, tem-se a nítida sensação de inferioridade da pesquisa científica e tecnológica aqui desenvolvida e de sua reduzida importância para a economia brasileira.

Não se deve, porém, ficar nesta constatação, pois é necessário descobrir como furar essa barreira cultural. Neste sentido, aponta- 
12 Esboçada desde muito antes, a carreira foi efetivada na década de 1980 durante a gestão do governador Franco Montoro, um dos fundadores e líderes do pensamento do PSDB. mos para o contraste com uma política como a que foi praticada, por exemplo, no Japão, que, além da já referida 'decolagem' no período Meiji, depois da derrota na Segunda Guerra Mundial, seguiu algumas estratégias que deram certo também em outros países e que no Brasil nunca foram suficientemente incentivadas. Entre estas, cabe uma referência em especial à coordenação interministerial, ou seja, ciência e tecnologia deveriam fazer parte de uma política mais ampla (indústria, comércio, saúde, infraestrutura geral), para otimizar os esforços de pesquisa e desenvolvimento, além de garantir que saíssem do papel e se tornassem efetivos na sua aplicação para a sociedade - iniciativas que se poderiam estender da esfera federal para a estadual.

Em nossa opinião, o quadro nos países atrasados como o Brasil tem-se agravado com a ideologia da globalização, uma vez que foram fechadas várias linhas de produção nacional, e a pouca pesquisa que lhes era associada deixou de ter interesse para as multinacionais, que passaram a trazer prontos seus produtos de fora do país. Freqüentemente, como no caso das indústrias elétricas e eletrônicas, essas empresas deixaram até de praticar a antiga 'tropicalização' de seus produtos, o que pelo menos exigia alguma pesquisa de materiais e processos para um funcionamento a contento em condições diversas daquelas para as quais tinham sido projetados. Muitas das próprias empresas nacionais que não agüentaram a competição predatória de preços se transformaram em meros entrepostos de importação/exportação, perdendo a capacitação tecnológica antigamente adquirida em favor de seus concorrentes estrangeiros. A percepção de que existe uma correlação entre o neoliberalismo e a decadência da pesquisa nos institutos de pesquisa científica não se trata de uma simples polarização política dos entrevistados.

Nos institutos paulistas de pesquisa, os problemas da carreira dos seus cientistas e o redirecionamento do escopo de suas atividades remontam a várias décadas de depreciação por parte das autoridades públicas, que já se observava há tempos, pelo menos desde a década de 1960. A própria estruturação da carreira de pesquisador científico ${ }^{12}$ encontrou resistências no seio da comunidade institucional, que viu nela uma forma de cobrar dos profissionais uma produção que valorizaria a produção de papéis e não de pesquisa. Todas essas dificuldades parecem ter se intensificado com a prática da política neoliberal, que fez com que aparecessem modelos de gestão estranhos à finalidade, incentivando o uso de chavões, tais como 'prestação de serviços', 'busca de resultados', 'auto-sustentação', e que, ao apregoar as virtudes da venda de serviços como pretensa integração à comunidade, relegou a pesquisa ao limbo da falta de verbas e apoio. 
O modelo paulista, que se orgulhava de ter um diferencial perante a maioria dos órgãos congêneres dos outros estados e mesmo dos federais, em conseqüência, vem tendendo a se igualar a estes no pior dos sentidos. Como resultado, a própria carreira de pesquisador nos institutos paulistas está ameaçada de extinção, seja pelo seu fim direto, seja pelo seu redirecionamento para atividades estranhas à pesquisa, tais como o mero preenchimento burocrático de laudos para empresas privadas, seja ainda pela aposentadoria e falta de renovação dos atuais pesquisadores remanescentes. Isso só não ocorreu de forma mais pronunciada devido ao elevado desemprego no mercado de biociências. De fato, tem havido grande procura por ocasião dos pouquíssimos concursos abertos nos institutos estaduais, o que mostra que os profissionais da área se submetem ao trabalho de pesquisa mesmo numa situação deteriorada.

Os impactos esperados com as transições para redefinir o papel dos institutos, ora intensificadas pelo atual governo estadual, são de que a pesquisa ficará cada vez mais a cargo das universidades; as universidades estaduais começam a sentir um novo problema, que é o da concorrência pelos recursos por parte das instituições privadas de ensino. Diz-se que aos institutos estaduais de pesquisa caberão atividades rotineiras, parecendo-nos que seu lugar possa futuramente até vir a ser tomado por setores da iniciativa privada, ligados ou não ao ensino superior.

Uma saída possível para esses dilemas seria que os institutos dedicassem parte de seu tempo a mais projetos voltados ao interesse da sociedade, mas desde que isso se conformasse com critérios efetivamente discutidos com a sociedade civil e não fosse decorrente de imposições de políticos ou de outros interesses. Não há como negar que as pesquisas dos institutos são importantes para as políticas públicas e são custeadas com dinheiro público, cabendo haver uma prestação de contas e um atendimento ao público, mas a própria sociedade poderia ser mais bem informada da necessidade de manutenção de pesquisas de caráter não imediatamente utilitário.

As transformações e os problemas reportados nos depoimentos têm tido apenas ocasionalmente alguma discussão pública no foro político estadual, em especial na esfera do poder legislativo, mas parece haver, acima de tudo, um descaso da própria comunidade científica para com a sorte dos institutos de pesquisa.

É oportuno enfatizar que não se trata aqui de um saudosismo quando se aponta que a história dessas instituições paulistas esteve ligada ao desenvolvimento econômico e social do estado. O que não deixa de ser lamentável é que o clima contemporâneo de acentuada 'desindustrialização', alto desemprego e forte violência social, acabe cobrando sua fatura também à pesquisa. Essas calamidades não chegaram vindo por uma simples 'geração espontânea', mas 
sim no bojo de um distanciamento do Estado do seu papel de indutor do desenvolvimento. O quadro é reversível? Parece que ainda há uma dose grande de idealismo nas pessoas que teimam em dedicar suas vidas a uma atividade tão mal reconhecida, de forma que caso houvesse uma reação da sociedade às perdas que se anunciam há tempos, os institutos poderiam ser recuperados e, eventualmente, até redirecionados, mas desde que se instituísse uma verdadeira política governamental de ciência e tecnologia, de longa duração e mais compromissada com essa sociedade do que com a política partidária e o poder.

Agradecimentos: o autor gostaria de registrar o reconhecimento pelo trabalho dos numerosos alunos de biologia da Universidade de São Paulo (USP) que colaboraram com as entrevistas, bem como a atenção concedida pelos entrevistados Carlos Jared, Durvanei Augusto Maria, Eliana Nakano, Harumi Ando Takehara, Henrique Moisés Canter, Isaías Raw, Marcelo Ribeiro Duarte, Maria Cristina Breno, Maria de Fátima Magalhães Lázari, Marta Maria Antoniazzi, Nancy Oguiura, Norma Yamanouye, Osvaldo Augusto Brazil Esteve Sant'Anna, Paulo Flávio Silveira, Roberto Henrique Pinto Moraes, Rogério Bertani, Toshie Kawano (Instituto Butantã); Cecília Blatt, Edson Paulo Chu, Eduardo Luís Martins Catarino, Helena Schoenlein-Crusius, Maria Cândida Henrique Mamede, Marina Capelari, Yara Struffaldi de Vuono (Instituto de Botânica); Celina Tizuko Fujiyama Oshima (Fundação Oncocentro); Cláudio Roberto Palombo (Secretaria do Meio Ambiente); Eliana de Stefano, Márcia Maria Rebouças, Mário Barreto Figueiredo, Olga Maria Russomano (Instituto Biológico); Paulo Edgard Nascimento de Toledo (Instituto de Economia Agrícola); Suzana Suindas (Instituto de Pesca).

\section{REFERÊNCIAS BIBLIOGRÁFICAS}

Almeida, Marta e

Dantes, Maria Amélia 2001

Bunge, Mario 1980

Dantes, Maria Amélia 1980

Gama, Ruy 1987

Izique, Cláudia abr. 2001

Lopes, Maria Margaret 1997

Pereira, José Carlos 1984

Pyenson, Lewis e Sheets-Pyenson, Susan 1999

Ribeiro, Maria

Alice Rosa 1993

Silva, Sérgio 1976

Teixeira, Luiz Antônio e Almeida, Marta 2003
O serviço sanitário em São Paulo, a saúde pública e a microbiologia. In Dantes, Maria Amélia (org.). Espaços da ciência no Brasil. Rio de Janeiro, Fiocruz.

Ciência e desenvolvimento.

São Paulo, Edusp. Belo Horizonte, Itatiaia.

Institutos de pesquisa científica no Brasil. In Ferri, M.e Motoyama, S. (coords.). História das Ciências no Brasil, v. 2, São Paulo, EPU/Edusp.

A tecnologia e o trabalho na história.

São Paulo, Nobel/Edusp

Nova arma contra a hipertensão arterial,

Pesquisa Fapesp, n. 63.

O Brasil descobre a pesquisa científica.

São Paulo, Hucitec.

Formação industrial do Brasil e outros estudos.

São Paulo, Hucitec.

Servants of nature.

Londres, Harper-Collins.

História sem fim...

São Paulo, Unesp.

Expansão cafeeira e origens da indústria no Brasil.

São Paulo, Alfa-Ômega.

Os primórdios da vacina antivariólica em São Paulo: uma história pouco conhecida. História, Ciências, Saúde - Manguinhos, v. 10, suplemento 2. 
Vargas, Milton

1994

Vargas, Milton

1985

Vogt, Carlos e

Stal, Vera (orgs.)

1994

Ziman, John

1981
Pesquisa tecnológica: seu papel na sociedade brasileira.

Para uma filosofia da tecnologia. São Paulo, Alfa-Ômega.

A metodologia da pesquisa tecnológica.

Rio de Janeiro, Globo.

Ciência e tecnologia: alicerces do desenvolvimento.

Brasília, CNPq.

A força do conhecimento.

São Paulo, Edusp.

Recebido para publicação em janeiro de 2004. Aprovado para publicação em novembro de 2004. 